\title{
Preliminary Investigation of Raindrop Size Distribution Modelling for Microwave Applications in Rwanda
}

\author{
Oluwumi Adetan \\ Department of Electrical and Electronic EngineeringEkiti State University, Nigeria
}

\begin{abstract}
The choice of rain drop size distribution(RDSD) model is essential for adequate estimation and prediction of attenuation due to rain in any geographical location or region. Measurements of drop size distributions at Butare $\left(2.6^{\circ} \mathrm{S}, 29.74^{\circ} \mathrm{E}\right)$; Rwanda is carried out using the Joss-WaldvogelRD- 80 disdrometer installed at the National University of Rwanda. Different established distributions are fitted to the measured disdrometer data to model the RDSD for a number of rainfall events. The method of moments (MoM) is adopted for the estimation of theRDSD parameters, while the scattering functions are estimated using the Mie scattering approximation at a temperature of $20^{\circ} \mathrm{C}$ for spherical raindrops. A comparative analysis of the proposed model is made with models from other tropical and equatorial regions. Theproposed models are used to estimate the specific rain attenuation over Rwandaand at $2.5-150 \mathrm{GHz}$ using the estimated $R_{0.01}$ value for Rwanda.Between $10 \leq f \leq 60 \mathrm{GHz}$ window, the specific rain attenuation increases with corresponding increase in the frequency. The performance above $60 \mathrm{GHz}$ relative to increase in frequency shows no significant change in the specific rain attenuation.The estimated attenuation statistics presented in this study will be useful for the proper design and allocation of adequate fade margins to achieve the expected quality of service (QoS) in a radio communication system operating in this region.
\end{abstract}

Keywords:-Raindrop size distribution models, method of moments, specific rain attenuation

\section{INTRODUCTION}

The understanding of the attenuation statistics is essential for the design of microwave and millimeterwave radio communication systems. It has been established that rain attenuation is more severe in these frequency bands as the rainfall intensity and attenuation vary in time and space [1]. The specific rainfall attenuation is often predicted from three parameters, which are the frequency, rain rate and polarization, where the population of the raindrops is represented by the single parameter, rainfall rate [2]. A good knowledge of the drop size distribution (DSD) is very important in the evaluation of the rainfall attenuation at these radio frequency bands because it governs all the microwave and rainfall integral relations. The modeling of the DSD varies from one climate to another. Drop size distribution modeling in temperate climate; characterized by moderate rainfall is well suitable with models such as proposed by Marshall and Palmer [3], Laws and Parsons [4] and the negative exponential model of gamma [5]. Tropical, subtropical and equatorial regions are characterized by high-intensity rainfall, enhanced frequency of rainfall occurrence and increased presence of large raindrops [6]. Oftentimes rain in the tropics occur in form of cells which are acomplex mixture of stratiform and convective types, with the convective rain contributing over 70 percent of the total rainfall in most cases [7,8].The modeling of DSD in the tropical climate is best suitable with the globally accepted Ajayi and Olsen [6] lognormal model. It has also been established that the three-parameter DSD models are more flexible than two-parameter models in the measurement and estimation of raindrop sizes variability and ensures high representability of the experimented measurement [9].

\section{CHARACTERISTICS OF RAINFALL IN RWANDA}

Rwanda is a land-locked country located in Central Africa, only twodegrees south of the equator, surrounded by the Democratic Republic of the Congo, Uganda, Tanzania and Burundi [Figure 1]. The country is characterized with two rainy seasons per annum. The first season occurs between February and May while the second season has been found to occur around September to December. During these seasons, heavy downpours occur almost daily, alternating with sunny weather. Rainfall is heaviest in the southwest and lightest in the east. At Gisovu, in the West, near Kibuye, annual rainfall averages $1600 \mathrm{~mm}$; at Gabiro, in the northeast, $780 \mathrm{~mm}$; and at Butare, in the south, $1150 \mathrm{~mm}$ [10]. The second largest city in Rwanda, Butare, where the measurement was taken using the disdrometer installed at the National University of Rwanda, is situated in the South and borders Burundi to the South. The city is at an elevation of 1772 meters above mean sea level. Rwanda is generally surrounded by mountains.Disdrometer measurements obtained from Butare are used to estimate the rain rate exceeded for $0.01 \%$ of time in Rwanda. Table 1 and Figure 2 show the complementary cumulative 
distributions functions (CDDF) of the rainfall rate $R(\mathrm{~mm} / \mathrm{h})$, exceeded for various percentages of time $P(\%)$ obtained at Butare, Rwanda.

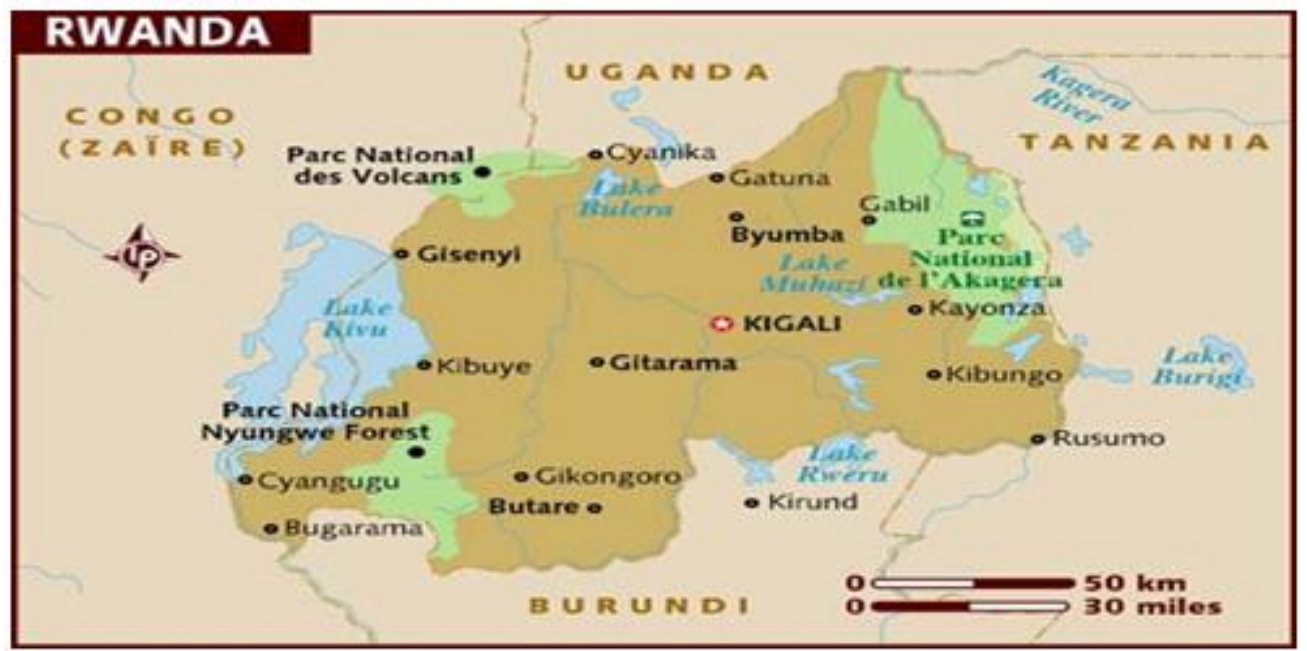

Figure 1: Map of Rwanda showing some of the neighboring countries [Source:https://www.google.co.za/\#q=map+of+rwanda]

Table 1: Estimated rain rate distribution at various percentages of exceedence in Rwanda.

\begin{tabular}{|c|c|c|c|c|c|c|c|c|}
\hline $\begin{array}{c}\text { Percentage of time rain } \\
\text { rate is exceeded (\%) }\end{array}$ & 2 & 1 & 0.5 & 0.3 & 0.2 & 0.1 & 0.05 & 0.01 \\
\hline Rain rate (mm/h) & 15.65 & 26.24 & 35.96 & 44.01 & 50.88 & 65.61 & 70.69 & 73.88 \\
\hline
\end{tabular}

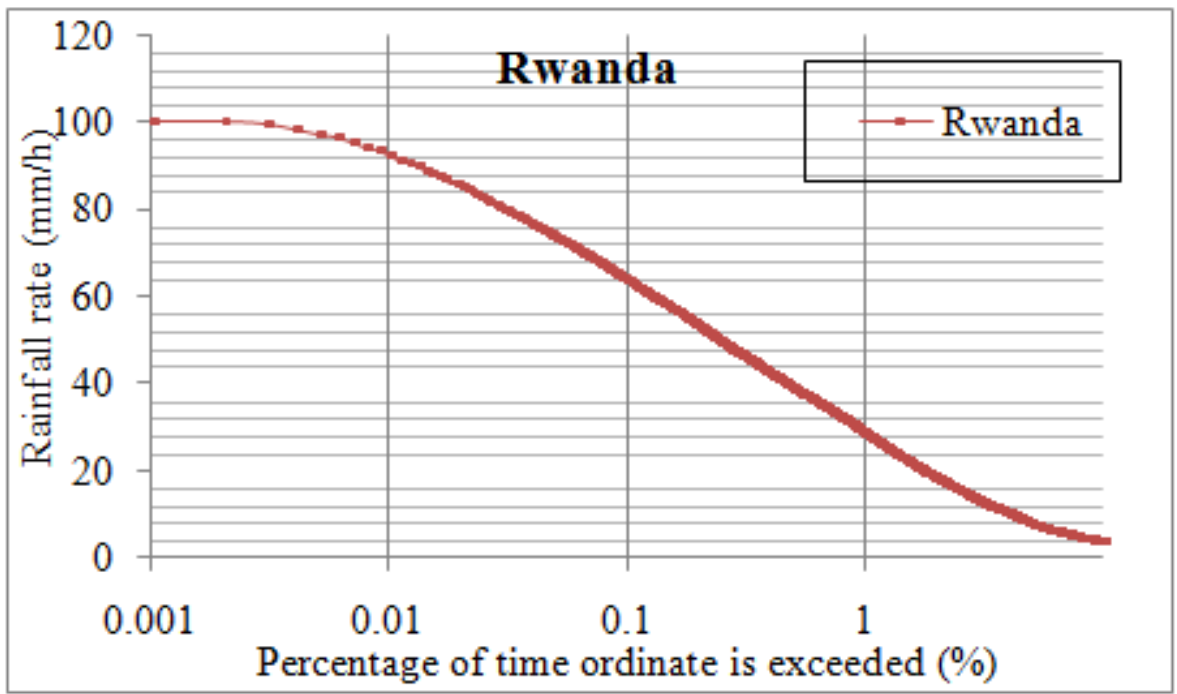

Figure 2: Complementary cumulative distributions of rain rate measured in Rwanda.

\section{DATA MEASUREMENTS, RDSD MOMENTS AND PARAMETER ESTIMATION}

\subsection{Data Measurements}

The Joss-Waldvogel (J-W) RD-80 [11] disdrometer installed at the National University of Rwanda, Butare was used to obtain data samples over a period of aboutone year in this study.The minimum and maximum rain rates obtained were $0.003 \mathrm{~mm} / \mathrm{hand} 78.15 \mathrm{~mm} / \mathrm{h}$ respectively. The disdrometer converts the momentum of each falling drop impacting on the sensor's surface into an electric pulse of commensurate voltage. The detectable diameter range is divided into 20 intervals. The sampling time, $T$ of the disdrometer is $60 s$ with the sampling area, $S$ of $50 \mathrm{~cm}^{2}\left(0.005 \mathrm{~m}^{2}\right)$. Rain events with overall sum of drops less than 10 were discarded from the data samples to compensate for the dead- time errors. The location is shielded from unwanted winds. Minimal equipment outage was observed during the period of data collection in this location. The raindrop size distribution is estimated from the disdrometer data as adopted by [12] using (1): 


$$
N\left(D_{i}\right)=\frac{n_{i} \times 10^{6}}{v\left(D_{i}\right) \times T \times S \times \Delta D_{i}}\left[m^{-3} m^{-1}\right]
$$

where $n_{i}$ is the number of drops measured in the drop size class, $T$ is the one-minute sampling time and $S$ is the sampling area.

\subsection{DSD Moments Estimation Technique}

The method of moments (MoM) was developed by Pearson [13]. The understanding of the moments of the DSD is necessary for the determination of the DSD evolution, and consequently of the rainfall rate [14]. The DSD moments represent most of the integral parameters of the drop size distribution. Since the method of moments uses a different function to individually estimate a given parameter, it is often easier and faster to calculate a method of moments estimate when more than one parameter is involved [15]. For radar-meteorology, the liquid water content (LWC) is proportional to the third order moment, the rainfall rate, $R$, is proportional to the 3.67 order moment (assuming that the terminal fall velocity is proportional to $\mathrm{D}^{0.67}$ ), and the reflectivity $(\mathrm{Z})$ is proportional to the sixth order moment. [14].TheMoM has been found useful for the estimation of parameters required for the modeling of drop size distribution especially in the tropical regions. Although it was first used by Waldvogel [16], a good number of researchers have found it useful. Notable among them include Ajayi and Olsen (1985) [6], in some selected locations in Nigeria; Timothy et al., (2002), in Singapore [7];Das et al., (2010) in tropical India [17]; Adetan and Afullo(2012) [18]; andAfullo (2011) in South Africa [19]. It has been established that the third, fourth and sixth moments are relevant to radio and microwave engineering studies [7, 17]. Generally, the $n$th ordermoment, $M_{n}$ as given by $[6,14]$ is expressed as:

$$
M_{n}=\int_{0}^{\infty} D^{n} \cdot N(D) d D
$$

where $D$ is the drop diameter in $\mathrm{mm}$ and $N(D)$ is the appropriate drop size distribution.

Equation (2) can be expressed in its discrete form as:

$$
M_{n}=\sum_{i=1}^{N} D_{i}^{n} N\left(D_{i}\right) \Delta D_{i}
$$

Equations (2) and (3) represent the $n$th moment function obtained from the disdrometer data. The appropriate drop size distribution is denoted by $N(D)$ for $\mathrm{N}$ rainfall samples and $D_{i}$ is the raindrop diameters for $\mathrm{N}$ discrete samples in $\mathrm{mm}$ and $\Delta D_{i}$ is the change in the diameter interval in $\mathrm{mm}$.

\subsection{Parameters Estimation}

Parameter estimation of drop size distribution is vital for the interpretation of radar and meteorological measurements and the estimation of radio wave due to rainfall. Generally, the measured DSD can be evaluated using:

$$
N(D)=f^{*}(D) \times N_{T}(D)
$$

where $N_{T}$ is the total number of raindrops for all sizes which is a function of the climates, geographical location of measurements and rainfall type and $f^{*}(D)$ is the density function. The various DSD models used in this workare described mathematically in the Appendix.

By using the method of moments estimation technique described in section 3.2, different input parameters for the described models, namely, Weibull, modified gamma, lognormal and the negative exponential are proposed for Butare. The input parameters based on the annual (overall) rainfall rate for these models arepresented in Table2. 
Preliminary Investigation of Raindrop Size Distribution Modelling for Microwave Applications in

Table 2:Estimated input DSD fit-parameters for different DSD models based in Rwanda

\begin{tabular}{|c|c|c|c|c|c|}
\hline \multicolumn{6}{|c|}{ WEILBULL RDSD MODEL } \\
\hline \multicolumn{2}{|c|}{$N_{o w}$} & \multicolumn{2}{|c|}{$\sigma_{w}$} & \multicolumn{2}{|c|}{$\eta$} \\
\hline \multicolumn{2}{|c|}{$147.27 R^{0.2459}$} & \multicolumn{2}{|c|}{$2.4363 R^{-0.114}$} & \multicolumn{2}{|c|}{$0.889 R^{0.1759}$} \\
\hline \multicolumn{6}{|c|}{ MODIFIED GAMMA RDSD MODEL } \\
\hline \multicolumn{2}{|c|}{$N_{o m}$} & \multicolumn{2}{|c|}{$\mu_{m}$} & \multicolumn{2}{|c|}{$\Lambda$} \\
\hline \multicolumn{2}{|c|}{$12020 R^{-0.429}$} & \multicolumn{2}{|l|}{2} & \multicolumn{2}{|c|}{$4.8049 R^{-0.21}$} \\
\hline \multicolumn{6}{|c|}{ LOGNORMAL RDSD MODEL } \\
\hline \multicolumn{2}{|c|}{$N_{T}$} & \multicolumn{2}{|c|}{$\mu_{l}$} & \multicolumn{2}{|c|}{$\sigma_{l}^{2}$} \\
\hline$a_{0}$ & $b_{0}$ & $A_{\mu}$ & $B_{\mu}$ & $A_{\sigma}$ & $B_{\sigma}$ \\
\hline 93.34 & 0.2371 & -0.0337 & 0.1835 & 0.0731 & 0.0076 \\
\hline \multicolumn{6}{|c|}{ NEGATIVE EXPONENTIAL RDSD MODEL } \\
\hline \multicolumn{3}{|c|}{$\Lambda$} & \multicolumn{3}{|l|}{$N_{o}$} \\
\hline \multicolumn{3}{|c|}{$3.2033 R^{-0.21}$} & \multicolumn{3}{|c|}{$2056.9 R^{-0.019}$} \\
\hline
\end{tabular}

\section{RAINFALL RATE AND SPECIFIC ATTENUATION DUE TO RAIN}

From a drop size distribution, the rainfall rate $R(\mathrm{~mm} / \mathrm{h})$ and the specific attenuation due to rainfall $\gamma(\mathrm{dB} / \mathrm{km})$ can be calculated by applying the integral equations in $(5,6)$ as:

$$
\begin{gathered}
R=6 \pi \times 10^{-4} \int_{0}^{\infty} v\left(D_{i}\right) \times D_{i}{ }^{3} \times N\left(D_{i}\right) \Delta D_{i}\left[\frac{\mathrm{mm}}{\mathrm{h}}\right] \\
\gamma=4.343 \times 10^{-3} \int_{d}^{d_{\max }} Q_{\text {ext }}\left(D_{i}\right) \times N\left(D_{i}\right) \Delta D_{i}\left[\frac{\mathrm{dB}}{\mathrm{km}}\right]
\end{gathered}
$$

where $R$ is the rainfall rate in $m m / h, v\left(D_{i}\right)$ is the terminal velocity of Gun Kinzer[20] in $m / s$, and $N\left(D_{i}\right) \Delta D_{i}$ is the number of drops per unit volume with diameter intervals $D$ and $D+d D, D_{i}$ is the raindrop diameters in $m m, Q_{\text {ext }}$ is the extinction cross sections which is dependent on the drop diameter $D$, the wavelength $\lambda$, and the complex refractive index of water drop $m$ (a function of frequency of transmission $f$, and temperature of water droplets).

It should be mentioned that equation (5) must not be violated by any DSD as it translates the principles of conservation of the raindrops. The extinction cross sections $Q_{\text {ext }}$ is evaluated by applying the classical scattering theory of Mie [21] for a plane wave impinging upon a spherical absorbing particle under the assumption that each spherical raindrop illuminated by a plane wave is uniformly distributed in a rain filled medium. The distance between each drop is also assumed large enough to avoid any interaction between them. The cross section $Q_{e x t}$ can be expressed by [22,23] in (7) as:

$$
Q(D, \lambda, m)=\frac{\lambda^{2}}{2 \pi} \sum_{n=1}^{\infty}(2 n+1) \operatorname{Re}\left[a_{n}+b_{n}\right]
$$


where $a_{n}$ and $b_{n}$ are the Mie scattering coefficients.The cross section in (7) can further be simplified and expressed in terms of the rainfall rate, $R$ as given by [21]:

$$
Q=\kappa\left(\frac{D}{2}\right)^{\alpha}
$$

where $\kappa$ and $\alpha$ are the Mie scattering coefficients. These parameters were computed by [24] at an ambient temperature of $20^{\circ} \mathrm{C}$ for different frequencies up to $500 \mathrm{GHz}$ for Durban, South Africa and Butare and adopted in this work.

\section{RESULTS AND DISCUSSIONS}

\section{a. Variability of DSD Modeling in Durban, South Africa}

This variability of the developed drop size distribution models with rain rates using the estimated input parameters in Table 2is analysed in this section. The different DSD models are fitted to the raindrop size distribution as spectra observed from the J-W disdrometer at Butare. The plots are shown in Figures 3(a)to3(e) for different rain rates. Firstly, an intrinsic change in the shapes of the DSD is observed as rain rate increases. In other words, the coverage area (diameter region) of the drop size distribution gets wider as the rain rate increases. In Figure $3 \mathrm{a}(\mathrm{R}=4.40 \mathrm{~mm} / \mathrm{h})$, the lognormal (LGM) model underestimates the measured data in the diameter range of 0.35 to about $0.8 \mathrm{~mm}$. The Weibull (WBM) and modified gamma (GMM) models seem to perform better when compared with the measured data at this low rain rate. At rain rate of about $35.20 \mathrm{~mm} / \mathrm{h}$, the shape of the DSD gets wider in the abscissa region. At this rain rate, the lognormal model gives a better fit. As the rain rate increases, the distribution of the droplets gets wider. The lognormal distribution shows a good agreement with the observed DSD spectra from the disdrometer but underestimates at the smaller diameter ranges. In other words, the modelled DSD and measured DSD show a proper fitting along a range of diameters. Similarly, using the estimated $R_{0.01}$ value for Butare, Rwanda $\left(R_{0.01}=73.88 \mathrm{~mm} / \mathrm{h}\right)$, the lognormal gives a better performance at this rain rate values when compared to other DSD models. In general, the Marshal-Palmer (MPM) DSD obviously overestimates the measured data for all the rain rates considered at the lower and higher drop diameter bounds, showing the inadequacy of the standard model in the region. It is obvious that the drop diameter increases for all the models as the rain rate increases. Although the gamma DSD also gives a better fit with the measured data, the lognormal model shows overall good agreement with the measured DSD especially at higher rain rate is more relevant for network planning.

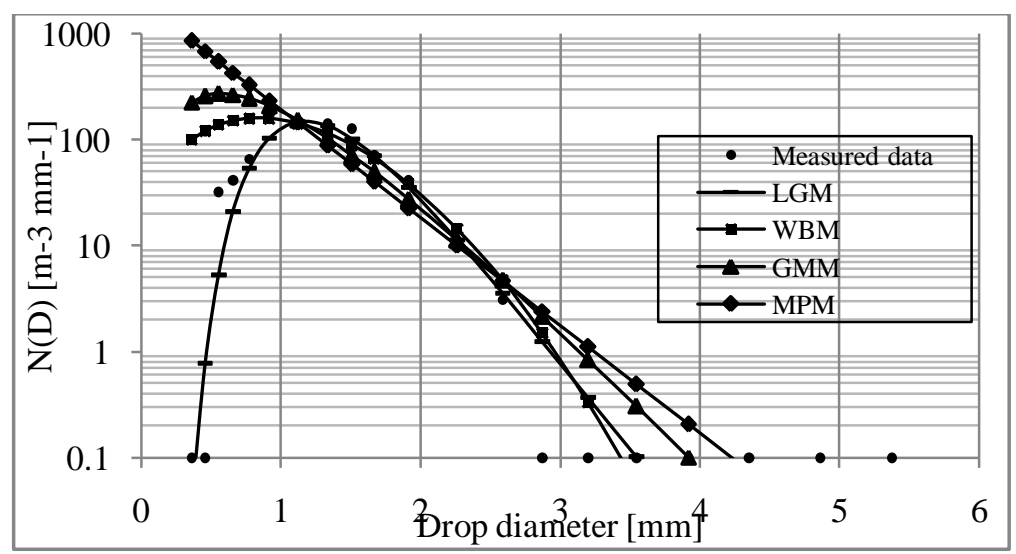

(a)

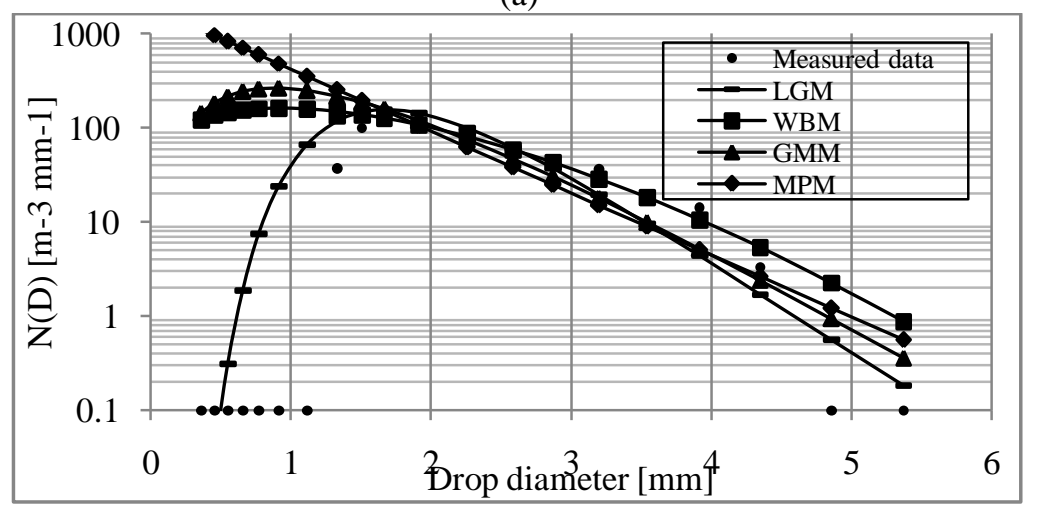


(b)

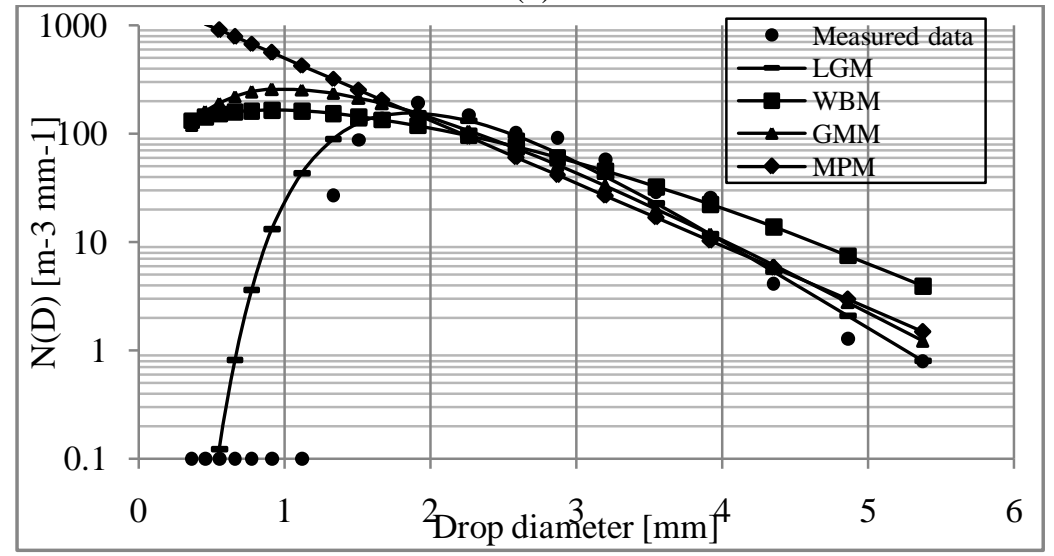

(c)

Figure 3: Different DSD models for Butare at $(a) R=4.40 \mathrm{~mm} / \mathrm{h},(b) R=35.20 \mathrm{~mm} / \mathrm{h},(\mathrm{c}) R=65.60 \mathrm{~mm} / \mathrm{h}$.

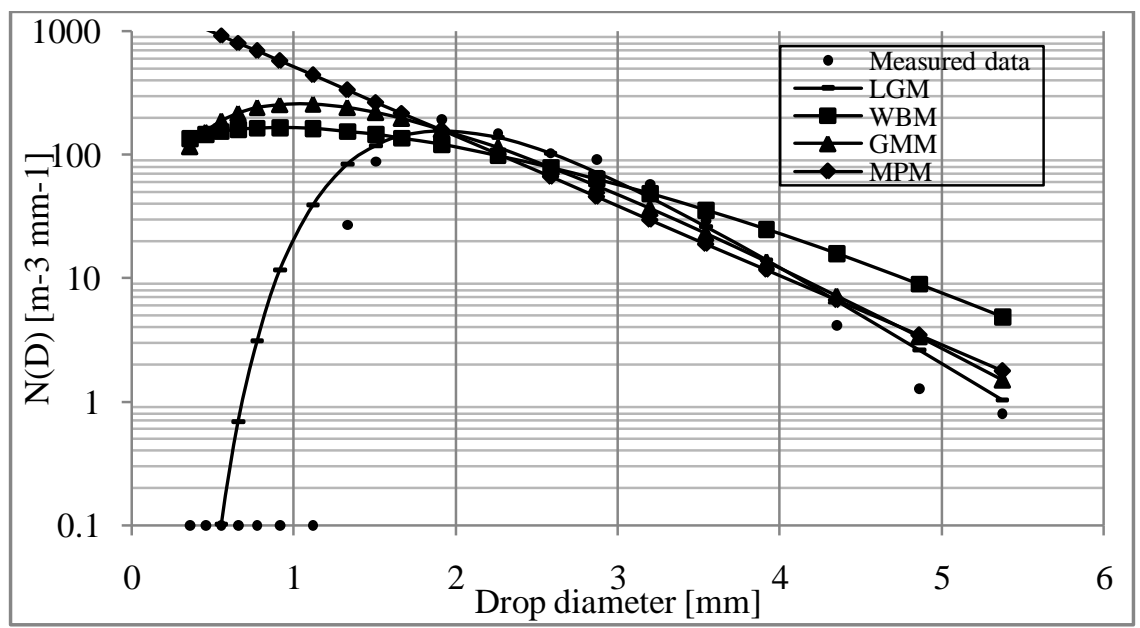

(d)

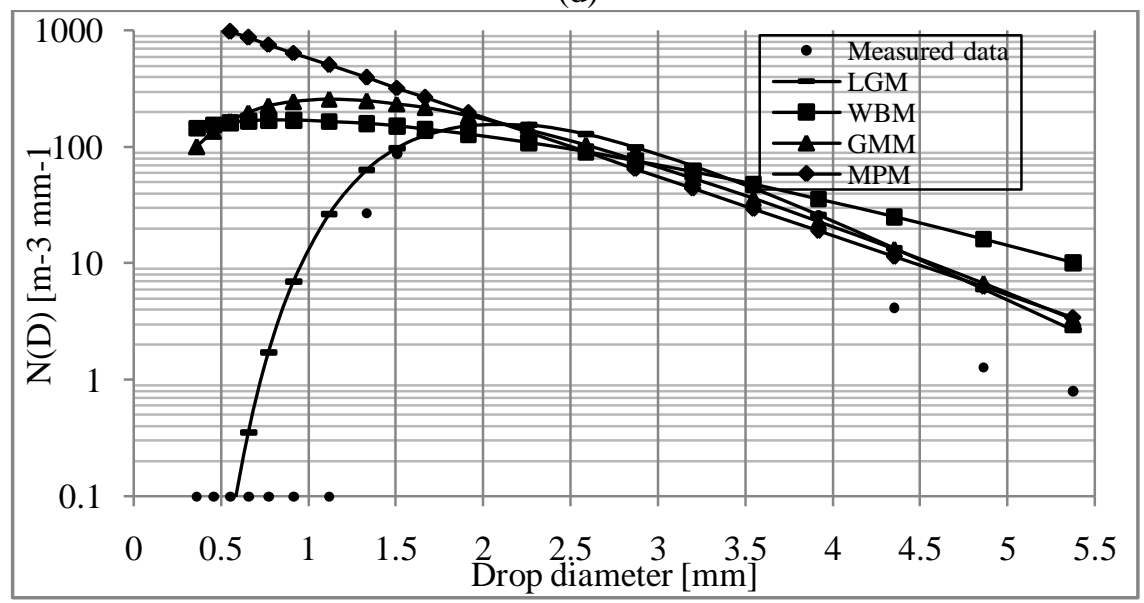

(e)

Figure 3: Different DSD models for Butare at (d) $R=73.88 \mathrm{~mm} / \mathrm{h}(e) R=120 \mathrm{~mm} / \mathrm{h}$

\section{b. Comparison with Other DSD Models}

A comparative analysis of the proposed modelin Butare, Rwanda with observations over other countries in the tropical, sub-tropical and equatorial regions is illustrated in Figures 4(a) and (b) at $R=25$ and $100 \mathrm{~mm} / \mathrm{h}$ respectively using the parameters in Table 3 . The lognormal $N(D)$ coefficients for the countries shown in the Table 3 are those obtained from [6] for Nigeria, [25] for India, [26] for Malaysia, and [7] for Singapore. For the two rain rates considered, the Indian $N(D)$ gives the highest peak followed by Singapore. The India and Singapore distributions however show the narrowest distributions compared to other countries in the 
regions. Although the DSD for Rwanda and Nigeria covers a wider distribution up to $5.5 \mathrm{~mm}$, they have the lowest DSDs compared to other countries. Malaysia and South Africa distributions are similar at diameters below $1 \mathrm{~mm}$ at these rain rates.

Table 3:Coefficients of lognormal for some tropical countries

\begin{tabular}{|c|c|c|c|c|c|c|}
\hline Coefficients & $\begin{array}{c}\text { Rwanda } \\
\text { (Proposed) }\end{array}$ & South Africa & Nigeria & Malaysia & India & Singapore \\
\hline$a_{0}$ & 93.34 & 215.15 & 108 & 45.33 & 546 & 276.18 \\
\hline$b_{0}$ & 0.237 & 0.320 & 0.363 & 0.6703 & 0.469 & 0.382 \\
\hline$A_{\mu}$ & -0.034 & -0.252 & -0.195 & -0.391 & -0.538 & -0.429 \\
\hline$B_{\mu}$ & 0.184 & 0.156 & 0.199 & 0.187 & 0.017 & 0.146 \\
\hline$A_{\sigma}$ & 0.073 & 0.073 & 0.137 & 0.407 & 0.069 & 0.156 \\
\hline$B_{\sigma}$ & 0.008 & 0.009 & 0.013 & -0.059 & 0.076 & 0.009 \\
\hline
\end{tabular}

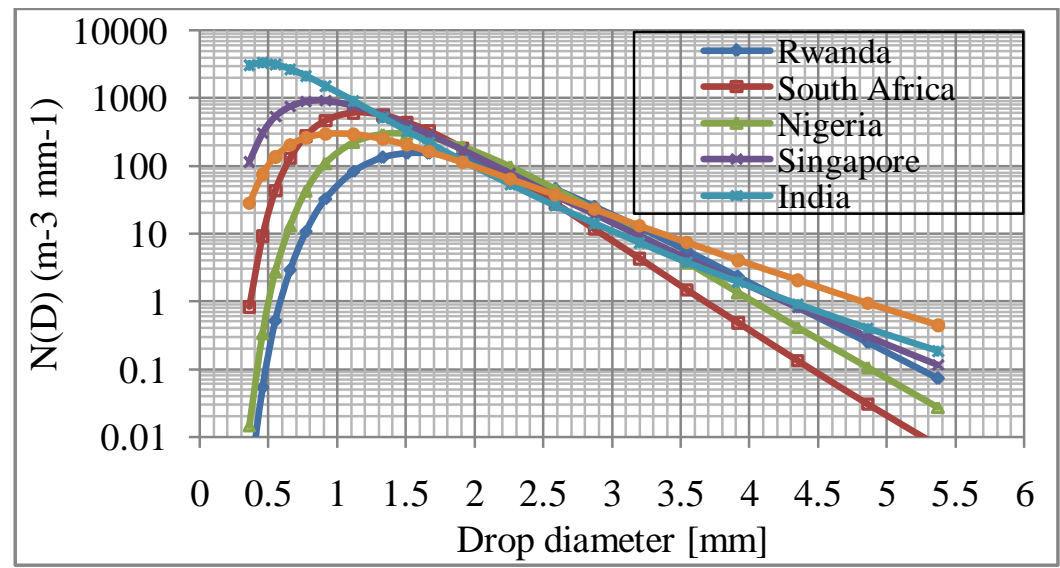

(a)

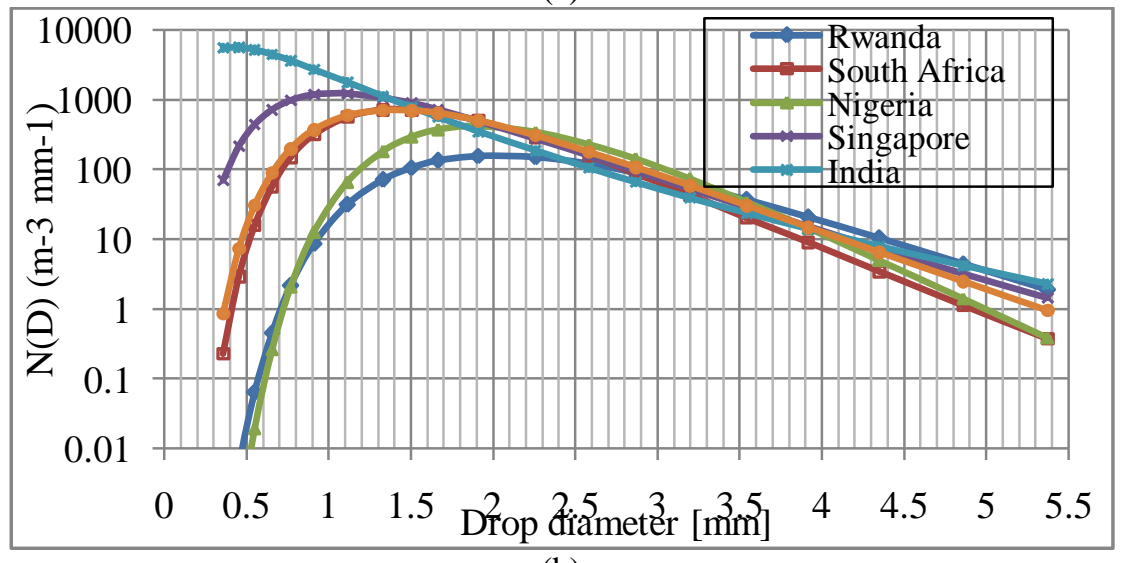

(b)

Figure 4:Comparison of the drop size distribution variations in the tropical, sub-tropical and equatorial regions (a) $R=25 \mathrm{~mm} / \mathrm{h}$ (b) $R=100 \mathrm{~mm} / \mathrm{h}$

The specific attenuation due to rainfall in Butare is computedusing equations (6) and (8). Table 4 shows variation of the attenuation with the transmission frequency. From the estimated attenuation values in Table 4 using the lognormal DSD model, it can be observed that, as the frequency increases, the attenuation also increases. However, at an operating frequency above $60 \mathrm{GHz}$, there is no significant increase in the specific attenuation due to rain in Butare.

Table 4:Specific attenuation computed using the lognormal DSD in Rwanda

\begin{tabular}{|l|l|l|l|l|l|l|l|l|}
\hline Operating Frequency $(\mathrm{GHz})$ & 2.5 & 10 & 19.5 & 40 & 60 & 80 & 100 & 150 \\
\hline Specific Attenuation $(\mathrm{dB} / \mathrm{km})$ & 0.01 & 1.67 & 5.98 & 11.51 & 13.21 & 13.61 & 13.66 & 13.31 \\
\hline
\end{tabular}




\section{CONCLUSION}

Raindrop size distribution measurements obtained from Butare, Rwanda, an equatorial region in Africa has been analyzed in this study. The proposed three-parameter lognormal and gamma models are adequate for the modeling of the drop size distributions at this location. The modeled distributions are also compared with those of some countries in the tropical, subtropical and equatorial regions. The specific attenuation due to rain was estimated. It should be mentioned that the results in this work is a preliminary investigation as the data used is not sufficient to give an affirmative prediction of the attenuation due to rain in this region. More data and link measurements are required to ascertain the results obtained in this study. However, adequate knowledge of this estimated attenuation characteristics will be necessary for predicting the accurate fade margin, required to achieve the expected quality of service on radio communication systems operating in this location for link budget designs on satellite and terrestrial links.

\section{ACKNOWLEDGEMENTS}

The author is grateful to Dr. Felix Akorli of the National University of Rwanda for providing the disdrometer data from Butare, Rwanda. The financial assistance from TETFUND Nigeria is also appreciated.

\section{REFERENCES}

[1] G. Hendrantoroand I. Zawadzki, "Derivation of parameters of Y-Z power-law relation from raindrop size distribution measurements and its application in the calculation of rain attenuation from radar reflectivity factor measurements," IEEE Trans on antenna and propagation, vol. 51, no. 1, 2003.

[2] "Specific attenuation model for rain use in prediction models," The Radiocommunications Agency of The International Telecommunications Union, ITU-R Recommendation P.838-3, 2005.

[3] J.S. Marshalland W.M. Palmer,"The distribution of raindrops with size," J. Meteor. 5, pp.165-166, 1948.

[4] J.O. Lawsand D.A. Parsons, "The relation of raindrops size to intensity," Trans. Am. Geophys. Union,24, pp. 452-460, 1943.

[5] D. Atlas andC.W. Ulbrich, "The Physical basis for attenuation-rainfall relationships and the measurement of rainfall parameters by combined attenuation and radar methods," J. Rech. Atmos., 8, pp.275-298, 1974.

[6] G.O. Ajayiand R.L. Olsen, "Modeling of a tropicalraindrop size distribution for microwave and millimeter wave applications," Radio Sci. vol. 20, no 2, pp.193-202, 1985.

[7] K.I. Timothy, J.T. Ongand E.B. Choo,"Raindrop size distribution using method of moments for terrestrial and satellite communication applications in Singapore," Antennas and Propagation, IEEE Transactions on, vol. 50, pp. 1420-1424, 2002.

[8] G.O. Ajayi,"Some aspects of tropical rainfall and their effect on microwave propagation," International Journal of Satellite Communications, vol. 8, pp. 163-172, 1990.

[9] A. Maitra,Three-parameter raindrop size distribution modeling at a tropical location". IEEE Electronic Letters, 36(10), $11^{\text {th }}$ May, 2000, pp.906-907

[10] http://www.nationsencyclopedia.com/Africa/Rwanda-CLIMATE.html.

[11] M. Montopoli, F.S. Marzano andG.Vulpiani, "Analysis and synthesis of raindrop size distribution time series from disdrometer data," IEEE Trans.Geosc., Remote Sens., 46(2), Feb, 2008, pp. 466-478.

[12] K. Pearson, "Skew variation in homogeneous material," Philosophical Trans., of the Royal Soc,, of London, 186, series A, pp.414-895, 1895.

[13] C. Caracciolo, F. Prodi,A. Battaglia, and F. Porcu, "Analysis of the moments and parameters of gamma DSD to infer precipitation properties: A convective stratiform discrimination algorithm," Atm. Research. 80, pp.165-186, 2006.

[14] A. Evans, "Maximum likelihood estimation," Advanced Biometry Spring, 2008.

[15] A. Waldvogel,"The No jump of raindrop spectra," Journal of the Atmospheric Sciences, vol. 31, pp. 1067-1078, 1974.

[16] S. Das,A. Maitra and A.K.Shukla,"Rain attenuation modeling in the 10-100 GHz frequency using drop size distributions for different climatic zones in tropical India," Progress in Electromagnetics Research, vol. 25, pp. 211-224, 2010.

[17] O. Adetanand T.J. Afullo,"Three-parameter raindrop size distribution modeling for microwave propagation in South Africa," Proceedings of The International Association of Science and Technology for Development (IASTED), International Conference on Modeling and Simulation (Africa MS 2012), Gaborone, Botswana,DOI:10-2316/P.2012.761-027, pp. 155-160, September 3-5, 2012.

[18] T.J.O. Afullo,"Raindrop size distribution modelling for radio link along the Eastern coast of South Africa," PIERS B, vol.34, pp.345-366, 2011.

[19] M.J. Bartholomew, "Disdrometer and tipping bucket rain gauge handbook," DOE/SC-ARM/TR-079, ARM Climate Research Facility, December 2009. 
[20] R. Gunand G.D. Kinzer, “Terminal velocity of fall for water drops in stagnant air”, J.Appl. Meteorology, 6, 1949, pp. 243-248.

[21] C. Mätzler., "Drop-size distributions and Mie computation,"IAP Research Report 2002- 16, University of Bern, Bern, November 2002.

[22] H.C. Van de Hulst,"Light Scattering by Small Particles," John Wiley and Sons Inc., $\quad$ New York, 1957.

[23] C.F. Bohren andD.R. Huffman, "Absorption and Scattering of Light by Small Particles," John Wiley, Wienheim, 2004.

[24] O. Adetan, "Modelling of raindrop size distribution and critical diameters for rainfall attenuation over microwave links in Southern Africa, Dissertation submitted to the University of KwaZulu-Natal, Durban, South Africa, January, 2014.

[25] A. Maitra,"Rain attenuation modeling from measurements of rain drop size distribution in the Indian region," Antennas and Wireless Propagation Letters, IEEE, vol. 3, pp. 180-181, 2004.

[26] U. Kesavan,A.R.Tharek,K.A.R. Sharul and M.I. Rafiqul,: 'Review of rain attenuation studies in Tropical and Equatorial regions in Malaysia: An Overview,' IEEE antennas and propagation, February 2013, 55, (1), pp.103-113.

\section{Appendix}

\section{Weibull DSD Model}

$$
(D)=N_{0}\left(\frac{\eta}{\sigma}\right)\left(\frac{D}{\sigma}\right)^{\eta-1} \exp \left\{-\left(\frac{D}{\sigma}\right)^{\eta}\right\}\left[m^{-3} m m^{-1}\right]
$$

The power law regression coefficients with respect to the precipitation rate $R$ are given as:

\section{Modified gammaDSD model}

$$
\begin{gathered}
N_{0}=a R^{b} \\
\eta_{\eta}=a_{\eta} R^{b_{\eta}} \\
\sigma_{\sigma}=\mathrm{a}_{\sigma} R^{b_{\sigma}}
\end{gathered}
$$

$$
N\left(D_{i}\right)=N_{0} D^{\mu} \exp (-\Lambda D) \quad\left[m^{-3} m m^{-1}\right]
$$

where $a, b, a_{g}$ and $b_{g}$ are the regression coefficients of input parameters with respect to the gamma model

$$
\begin{gathered}
N_{0}=a R^{b} \\
\Lambda=a_{g} R^{b_{g}}
\end{gathered}
$$

In most cases, the parameter $\mu$ takes the value of a constant which can be from 0 to 4 . In this study, the value of 2 is assumed.

\section{Lognormal DSD Model}

$$
\begin{gathered}
N(D)=\frac{N_{T}}{\sigma D \sqrt{2 \pi}} \exp \left\{-\frac{1}{2}\left[\frac{\ln D-\mu}{\sigma}\right]^{2}\right\} \quad\left[m^{-3} m^{-1}\right] \\
N_{T}=\exp \left[\left(24 L_{3}-27 L_{4}+6 L_{6}\right) / 3\right] \\
\mu=\left(-10 L_{3}+13.5 L_{4}-3.5 L_{6}\right) / 3 \\
\sigma^{2}=\left(2 L_{3}-3 L_{4}+L_{6}\right) / 3
\end{gathered}
$$

where $L_{3}, L_{4}$ and $L_{6}$ are considered the natural logarithms of the measured moments $M_{3}, M_{4}$ and $M_{6}$. These moments are related to the rain rate, the kinetic energy and radar reflectivity which are essential in rainfall retrieval and hydrological studies [13]. They are computed from the observed spectrum for each event. These can also be expressed as a function of rain rate $R$ in $\mathrm{mm} / \mathrm{h}$

$$
\begin{gathered}
N_{T}=a_{o} R^{b_{o}} \\
\mu=A_{\mu}+B_{\mu} \ln (R) \\
\sigma^{2}=A_{\sigma}+B_{\sigma} \ln (R)
\end{gathered}
$$

where $a_{o}, b_{o}, A_{\mu}, B_{\mu}, A_{\sigma}, B_{\sigma}$ are coefficients of moment regression [6].

4. Marshall Palmer DSD or Negative Exponential model

$$
N(D)=N_{0} \exp (-\Lambda D)\left(\text { for } 0 \leq D \leq D_{\max }\right)
$$

